This is the author's final, peer-reviewed manuscript as accepted for publication. The publisher-formatted version may be available through the publisher's web site or your institution's library.

\title{
Water stress is a component of cold acclimation process essential for inducing full freezing tolerance in strawberry
}

C. B. Rajashekar and Manasa Panda

\section{How to cite this manuscript}

If you make reference to this version of the manuscript, use the following information:

Rajashekar, C. B., \& Panda, M. (2014). Water stress is a component of cold acclimation process essential for inducing full freezing tolerance in strawberry. Retrieved from http://krex.ksu.edu

\section{Published Version Information}

Citation: Rajashekar, C. B., \& Panda, M. (2014). Water stress is a component of cold acclimation process essential for inducing full freezing tolerance in strawberry. Scientia Horticulturae, 174, 54-59.

Copyright: () 2014 Elsevier B.V.

Digital Object Identifier (DOI): doi:10.1016/j.scienta.2014.05.007

Publisher's Link: http://www.sciencedirect.com/science/article/pii/S0304423814002611

This item was retrieved from the K-State Research Exchange (K-REx), the institutional repository of Kansas State University. K-REx is available at http://krex.ksu.edu 
Water stress is a component of cold acclimation process essential for inducing full freezing tolerance in strawberry

C. B. Rajashekar ${ }^{1}$ and Manasa Panda

Department of Horticulture, Forestry and Recreation Resources, Kansas State University, Manhattan, KS 66506, USA

${ }^{1}$ Corresponding author: C. B. Rajashekar, Horticulture, Kansas State University, Manhattan, KS 66506, USA

crajashe@,ksu.edu

Ph: 785-532-1427

Fax:785-532-6949 
Keywords: Freezing tolerance

Cold hardening

Cold-responsive genes

Drought 


\section{Highlights}

- Low temperature and water stress are two components of cold acclimation in strawberry.

- Water stress plays a dominant role in inducing freezing tolerance.

- These components can independently induce freezing tolerance and are additive.

- These components also induce COR gene orthologs similar to cold acclimation. 


\begin{abstract}
The factors involved in cold acclimation process and their role in inducing freezing tolerance were studied in strawberry (Fragaria $X$ ananassa) plants. The results show that low temperature and water stress are two key components of cold acclimation, in that low temperature typically induced water stress in the plants. After a 2 -week exposure of plants to $3 / 1^{\circ} \mathrm{C}$ (day/night temperature), the leaf water potential decreased markedly to below -1.6 MPa. While both of these components contribute significantly to the induction of freezing tolerance, water stress is a dominant factor in inducing freezing tolerance, contributing roughly to $56 \%$ of freezing tolerance acquired by natural cold acclimation. Typical cold acclimation treatment of plants for 2 weeks increased their freezing tolerance by about $14^{\circ} \mathrm{C}$ to $-20.7^{\circ} \mathrm{C}$ while the same treatment, in the absence of the accompanying water stress, increased their freezing tolerance only by $5^{\circ} \mathrm{C}$, which indicates the importance of water stress during cold acclimation. Furthermore, both low temperature and water stress independently induced the orthologs of cold-responsive genes, COR47 and COR78, however, stronger expression of these genes was observed in response to cold acclimating conditions. Thus, these results show that both of these factors are essential elements of cold acclimation process and play an important role in inducing freezing tolerance in strawberry plants.
\end{abstract}




\section{Introduction}

Temperate plants have the ability to increase their freezing tolerance in response to acclimating conditions which typically include low temperatures and short days (Howell and Weiser, 1970). Cold acclimation is a complex process involving many morphological, physiological and biochemical changes (Levitt, 1980; Steponkus, 1984; Guy, 1990) including a significant decrease in tissue hydration during cold hardening process (Levitt, 1980). Dehydration has long been observed during cold hardening in a wide range of both herbaceous as well as woody plant species (Mckenzie et al., 1974; Cox and Levitt, 1976; Guy et al, 1992; Lang et al., 1994). Nonetheless, it is not clear if water stress induced during cold hardening plays any role in inducing freezing tolerance in plants or whether it is an integral part of typical cold hardening process. Furthermore, there has been an overwhelming evidence that shows water stress alone, in the absence of low temperatures, can induce freezing tolerance in a number of plant species including Arabidopsis, wheat, oats, rye and many others (Chen et al., 1975; Cloutier and Siminovitch, 1982; Cloutier and Andrews, 1984; Lang et al., 1994; Mantyla et al., 1995). In many cases, water stress was found to be as effective as typical cold acclimating conditions in inducing freezing tolerance (Cloutier and Siminovitch, 1982; Mantyla et al., 1995). From these studies, it follows that when plants are subjected to cold acclimation treatment they are likely to experience not only low temperature but also water stress induced by the low temperature. The two components of cold acclimation individually may contribute to the freezing tolerance, but their role is not fully understood and more importantly, they are not recognized as two separate signals that may independently act in inducing freezing tolerance in plants. 
This may be, in part, because the two components of cold acclimation are often difficult to distinguish as many of the plant responses to these stimuli are similar (Shinozaki et al., 2003). A review of molecular responses to cold and water stress reveals a number of significant similarities between them. In Arabidopsis, cold-inducible C-repeat binding factor (CBF) genes induce downstream both cold-responsive and drought-responsive genes (Pearce, 1999; Thomashaw, 1999; Shinozaki and Yamaguchi-Shinozaki, 2000). These target genes are regulated by a cis-acting C-repeat (CRT) or dehydration-responsive element (DRE) in their promoter regions. Both these promoter elements contain a common core motif (A/GCCGAC) which regulates a number of genes that respond to both cold and drought stresses. Furthermore, overexpression of CBF genes in Arabidopsis or their ectopic expression in other plant species is known to confer tolerance to multiple stresses including freezing and drought (Kasuga et al., 1999; Hsieh, 2002a, 2002b).

CBF orthologs have been identified in a number of plant species including both monocots and dicots (Jaglo et al., 2001; Kitashiba et al., 2004; Campoli et al., 2009; Carvallo et al., 2011) and appear to have similar functions as CBFs in inducing stress tolerance in these species. For example, Owens et al. (2002) characterized CBF1 ortholog in strawberry and found that it was upregulated in response to cold acclimation and that an heterologous expression of CBF1 in strawberry significantly increased the leaf freezing tolerance indicating the presence of CBF regulon in strawberry.

The objective of this study was to determine if water stress is an integral and an essential component of cold acclimation in strawberry plants and its possible role in inducing freezing tolerance. In addition, to further characterize the role of the components of cold acclimation, plant responses to low temperature and water stress with regard to the expression of orthologs of 
cold-responsive genes was examined. In this study, we characterize the role played by typical cold acclimation treatment and its components, namely low temperature and water stress in inducing freezing tolerance in strawberry plants.

\section{Materials and methods}

\subsection{Plant materials and growing conditions}

Strawberry (Fragaria $X$ ananassa, cv. Surecrop) plants were grown in $61 / 2$-inch pots containing soil mix (Metro Mix 350, Sun Gro Horticulture, Agawan, MA, USA) in a greenhouse at $23 / 18^{0} \mathrm{C}$ (day/night temperature) under natural daylight. The plants were watered once in 2 days and fertilized once every week with Peat-Lite special (N-P-K: 20-10-20, Everris, Marysville, OH, USA) at $250 \mathrm{ppm}$ of nitrogen in the irrigation water. Daughter plants were propagated periodically from mother plants as needed and were allowed to grow under similar conditions. Plants, at least 4 weeks old, were subjected to 3 acclimating conditions, namely, standard cold acclimating conditions (CA- low temperature and short photoperiod), low temperature (LT- standard acclimating condition minus the accompanying water stress) and water stress at $22^{\circ} \mathrm{C}$. The experiments were conducted using a completely randomized block deign with 3 replications, each containing 3 plants.

\subsection{Cold acclimation and drought treatments}

Plants were subjected to $\mathrm{CA}$ by transferring them to a walk-in cold room at $3 / 1^{0} \mathrm{C}$ (day/night temperature) with light intensity of $200 \mu \mathrm{mol} \mathrm{m} \mathrm{m}^{-2} \mathrm{~s}^{-1}$ and a photoperiod of 9 hours. Plants were acclimated for 2-3 weeks before evaluating for freezing tolerance. Plants were watered as needed, in order to keep the soil moist throughout this period.

To preclude water stress during cold acclimation (LT), plants were maintained under the above acclimating conditions except that the growing medium was maintained at field capacity 
while the growth chamber was maintained at $100 \%$ relative humidity. To maintain the growing medium at field capacity, pots were placed in clear plastic troughs [49 cm (L) x $35 \mathrm{~cm}$ (W) x 22 $\mathrm{cm}(\mathrm{H})]$ filled with water up to a height of $1 \mathrm{~cm}$. The troughs containing strawberry plants were then placed in a cold room maintained at $3 / 1{ }^{\circ} \mathrm{C}$ (day/night temeperature) and $100 \%$ relative humidity with $9 \mathrm{~h}$ photoperiod for 2-3 weeks.

To treat plants with water stress, strawberry plants were grown in $61 / 2$-inch pots, each containing approximately the equal amount of soil mix (Metro Mix 350). To induce water stress in the plants, water was withheld from plants for 10 days in a growth chamber set at $22^{\circ} \mathrm{C}$. The growing conditions were similar to those described above. During this period, leaf water potential was measured daily. Control plants were grown under identical conditions except that they received regular watering (to field capacity) every 2 days.

\subsection{Water potential measurements}

All leaf water potential measurements were made at the same time of the day in both control and water stressed plants and during cold acclimation at 1 h, 2 h, 4 h, 1 day, 2 days, 1 week, and 2 weeks of acclimation. The leaf water potential was measured using a pre-calibrated psychrometer (Model SC 10X, Decagon Device, WA, USA). Mature leaves were collected from the middle of the canopy and leaf disks of $1 \mathrm{~cm}$ in diameter were cut and immediately sealed in a stainless steel psychrometer chamber. The water potential was measured in a dew point mode. The samples were allowed to equilibrate for $30 \mathrm{~min}$ and the leaf water potentials were recorded with an $\mathrm{X}-\mathrm{Y}$ recorder. The water potential of each sample was determined as the average of three samples.

\subsection{Freezing tolerance evaluations}


Freezing tolerance evaluations were conducted using excised leaves. Leaves were placed in test tubes $(20 \times 2 \mathrm{~cm})$ and transferred to a circulating bath (Forma scientific, OH, USA) at approximately $0^{\circ} \mathrm{C}$. Samples were nucleated with crushed ice at $-1^{\circ} \mathrm{C}$ and held for $3 \mathrm{~h}$ at this temperature to ensure equilibrium freezing. Samples were cooled to $-22^{\circ} \mathrm{C}$ at $2{ }^{\circ} \mathrm{C} / \mathrm{h}$ and removed at various test temperature to evaluate the freezing injury. The temperature of the samples was monitored by a copper constantan thermocouple and recorded on an Omega chart recorder (Series 500). Samples were allowed to thaw at $3^{\circ} \mathrm{C}$ and their electrolytic leakage was measured. Approximately $20 \mathrm{ml}$ of double-distilled water were added to each test tube and the samples were agitated on an orbital shaker (LAB-LINE Instrument, IL, USA) for 10-12 $\mathrm{h}$ at room temperature. Conductance of the leachate was measured with an YSI conductance meter (Model-32, Yellow Spring Instrument Co. Inc., OH, USA). Samples were then autoclaved for 20 minutes at $121^{\circ} \mathrm{C}$ to release the total electrolytes from the sample. The samples were agitated for 10-12 hours again before making the final conductance measurement. The killing temperature was determined based on the electrolyte leakage (Rajashekar et al., 1983). The experiment was conducted with 3 replications on a completely randomized design.

\subsection{Gene expression analyses}

For DNA and RNA extractions, strawberry leaves (400 mg) were collected, immediately frozen in liquid nitrogen and stored at $-70{ }^{\circ} \mathrm{C}$ until use. To isolate DNA, frozen leaves were ground into powder in liquid nitrogen. A $3 \mathrm{ml}$ of extraction buffer $(2 \% \mathrm{CTAB}, 100 \mathrm{mM}$ Tris $\mathrm{pH}$ 8, $20 \mathrm{mM}$ EDTA, $1.4 \mathrm{M} \mathrm{NaCl}$ ) with $2 \% \mathrm{PVP}$ and $5 \% \beta$ - mercaptoethanol warmed up to $65^{\circ} \mathrm{C}$ was added to a mortar and was mixed well. Approximately $1 \mathrm{ml}$ of the homogenate was added to a tube with equal volume of phenol: chloroform and incubated at $65^{\circ} \mathrm{C}$ for $10 \mathrm{~min}$. Samples were then incubated for $10 \mathrm{~min}$ on ice and centrifuged at $8,000 \mathrm{~g}$ at $4^{\circ} \mathrm{C}$ for $10 \mathrm{~min}$. The upper phase 
of the solution was mixed with equal volume of ice-cold isoproponal and held at $-20^{\circ} \mathrm{C}$ for 30 min for DNA precipitation. The solution was centrifuged once again at $17,000 \mathrm{~g}$ for $20 \mathrm{~min}$. The white pellet at the bottom was washed with $70 \%$ ethanol, dried for 5 min and resuspended with $200 \mu \mathrm{l}$ sterile water. A $5 \mu \mathrm{l}$ of RNase $(10 \mathrm{mg} / \mathrm{ml})$ was added to the DNA and stored at $-20^{\circ} \mathrm{C}$ until needed.

Total RNA was extracted from the strawberry leaves by using the cetyltrimethylammonium bromide RNA extraction method (Fan et al., 1997) and stored in $-70^{\circ} \mathrm{C}$ until use. The RNA blot analyses were conducted following the procedure of Oh et al. (2009) with some modifications. RNA was subjected to $1 \%$ formaldehyde agarose denaturing gel electrophoresis and was subsequently transferred onto a nylon membrane (Sigma, St. Louis, MO, USA) in a 10 x SSC solution. The probes for the Arabidopsis COR gene orthologs, FaCOR47 and FaCOR78, were prepared using the following primers: FaCOR47: 5' TCG AGC GAT GAA GAA GGT GAG G 3' and 5' CTT CCT CTT CAG TGG TCT TGG C 3' and FaCOR78: 5' AGG AGT TGT TTT CCC GGT GGG C 3' and 5' CTG ATG CCT CAC CGT ATC CAG G-3'. These segments were amplified by PCR using strawberry DNA and were labeled with ${ }^{32} \mathrm{P}$ using the random primer DNA labeling system (Sigma, St. Louis, MO, USA). Following the prehybridization of nylon membranes (1 mM EDTA, $0.5 \mathrm{M}$ phosphates (pH 7.2), and 7\% SDS), the labeled probes were hybridized with RNA at $50^{\circ} \mathrm{C}$ for $16-18 \mathrm{~h}$ in prehybridization buffer solution with $0.9 \%$ BSA. The blots were washed twice with wash solution 1 [1 mM EDTA, $40 \mathrm{mM}$ phosphate buffer $(\mathrm{pH}$ 7.2), $5 \% \mathrm{SDS}$ ] and twice with wash solution 2 [1 mM EDTA, $40 \mathrm{mM}$ phosphate buffer (pH 7.2), $1 \% \mathrm{SDS}]$ at $65^{\circ} \mathrm{C}$ for $30 \mathrm{~min}$. They were then exposed in a phosphor-imager cassette at room temperature for 3-5 days and scanned using Image Quant software (Molecular Dynamics Inc., CA, USA). 


\section{Results and discussion}

\subsection{Water stress during cold acclimation}

Strawberry plants were cold-acclimated at $3 / 1^{\circ} \mathrm{C}$ with $9 \mathrm{~h}$ photoperiod (CA) for $2-3$ weeks. Freezing tolerance was evaluated based on the electrolyte leakage test on the leaves. The non-acclimated plants survived approximately $-6.7^{\circ} \mathrm{C}$. With one week of CA treatment, plants showed the largest increase in their freezing tolerance, surviving approximately $-20.7^{\circ} \mathrm{C}(\underline{\text { Fig. }}$. 1B). However, no significant increase in freezing tolerance was observed after 1 week CA treatment.

During the CA treatment, leaf water potentials were measured before and after $1 \mathrm{~h}, 2 \mathrm{~h}, 4$ h, 1 day, 2 days, 1 week, and 2 weeks of cold acclimation. The results showed there was a significant decrease in the leaf water potential within hours $(2-4 \mathrm{~h})$ of exposing the plants to acclimating conditions while the largest decrease occurred after 1 week of cold acclimation (Fig. 1A). The leaf water potential dropped from approximately $-1 \mathrm{MPa}$ to $-1.6 \mathrm{MPa}$ after 2 weeks of cold acclimation indicating significant water stress in strawberry plants during cold acclimation. These observations are consistent with numerous studies demonstrating dehydration during cold acclimation process in a wide ranging plant species (McKenzie et al., 1974; Cox and Levitt, 1976; Lang et al., 1994). In Arabidopsis seedlings, Lang et al. (1994) showed that low temperature can decrease the plant water potential over a number of days during cold acclimation treatment, but plants tend to recuperate from water stress, if they are transferred to warmer temperature $\left(22^{\circ} \mathrm{C}\right)$ during deacclimation, suggesting that the cold acclimation process is specifically involved in inducing water stress in these plants. 
To determine the role played by water stress-induced during cold hardening process in strawberry plants, water stress was precluded by exposing well-watered plants to the above acclimating conditions but at $100 \%$ relative humidity (LT). Based on the data on water status in plants, there was no apparent water loss from these plants. In fact, the leaf water potential increased slightly during the 2-week acclimation period (Fig. 1A). Thus, these plants were exposed to only low temperature without the accompanying water stress typically associated with CA. After 1 week of exposure of plants to low temperature, the plants had acquired the full potential freezing tolerance, just as in the CA treatments. However, the freezing tolerance of plants in response to $\mathrm{LT}$ was much lower $\left(-11.7^{\circ} \mathrm{C}\right)$ than to a typical CA treatment (Fig. 1C). As in the CA treatment, the LT treatment after 1 week did not increase the freezing tolerance of plants. This suggests that water stress induced during CA treatment plays a major role in inducing freezing tolerance in strawberry plants.

\subsection{Water stress and induction of freezing tolerance}

To assess the role played by water stress in inducing freezing tolerance, water stress was induced in strawberry plants by withholding water up to $8-10$ days at $22^{\circ} \mathrm{C}$. Freezing tolerance evaluations were conducted after 6 days and 9 days of water withholding, a period where sharp decrease in leaf water potential from $-0.97 \mathrm{MPa}$ to $-2.6 \mathrm{MPa}$ was observed (Fig. 2A). Water stress induced significant increase in freezing tolerance of strawberry plants. After 6 days of water stress, the freezing tolerance increased by more than 2 - fold to $-14.2^{\circ} \mathrm{C}$, as leaf water potential began to decrease (Figs. 2A and 2B). However, further decrease in water potential after 6 days of water withholding did not affect the freezing tolerance suggesting that the initial water stress was able to induce freezing tolerance. Thus, it is likely that water stress can trigger the 
cold acclimation process and can independently induce freezing tolerance in plants (Chen and $\mathrm{Li}$, 1978). Mantyla et al. (1995) compared freezing tolerance in Arabidopsis induced by water stress and cold acclimation treatment and found that water stress alone could induce freezing tolerance to similar levels as the cold acclimation treatment. Similar results were also observed in some cereal crops, while in others water stress was not as efficient as cold acclimating condition, although it could induce significant freezing tolerance (Cloutier and Cloutier and Siminovitch, 1982; Siminovitch and Cloutier, 1982; Andrews 1984). Our results are consistent with the above findings in which water stress significantly increases freezing tolerance but cannot entirely substitute the CA treatment in inducing full freezing tolerance in strawberry plants. However, considering that water stress is an important component of cold acclimation process and the avoidance of this during cold acclimation can severely hamper the ability of plants to fully cold harden suggests that water stress plays a key role in natural cold acclimation process in strawberry plants (Fig. 1) . Thus, we can conclude that strawberry plants are unable to acquire full freezing tolerance during cold acclimation process without the accompanying water stress. This may have considerable practical significance in natural cold acclimation of crops under field conditions in that applying excessive or late irrigation to crops in autumn may indeed have a significant adverse impact on their ability to fully cold harden.

\subsection{Role of water stress and low temperature in inducing freezing tolerance}

Figure $3 \mathrm{~A}$ shows the putative contributions of low temperature and water stress in inducing freezing tolerance in strawberry. The maximum increase in freezing tolerance in strawberry plants was observed in response to CA which reflects the natural cold acclimation process. In response to $\mathrm{CA}$, strawberry plants survived approximately $-20.7^{\circ} \mathrm{C}$, an increase in freezing 
tolerance by $14^{\circ} \mathrm{C}$ relative to the unhardened plants. However, exposure of strawberry plants to water stress increased their freezing tolerance by about $7.5^{\circ} \mathrm{C}$ while low temperature increased their freezing tolerance by about $5^{\circ} \mathrm{C}$ suggesting that water stress may play a more dominant role in inducing freezing tolerance than low temperature during natural cold acclimation. Nonetheless, both components of cold acclimation are needed for plants to acquire maximum freezing tolerance and appear to have an additive role in inducing freezing tolerance during cold acclimation (Fig. 3A).

\subsection{Expression of orthologs of cold-responsive genes}

Expression of the orthologs of COR genes was determined in strawberry plants subjected to CA, LT and water stress to delineate plant responses to these individual components of cold acclimation (Figs. $3 \mathrm{~B}$ and $\underline{3} \mathrm{C}$ ). Northern blot analyses were used to characterize the expression of cold-responsive genes including orthologs FaCOR47 and FaCOR78. Both these genes were

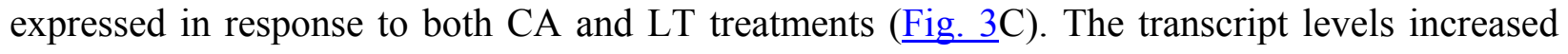
for FaCOR47 and were the highest after 1 week of CA treatment while, in contrast, in response to LT the transcripts accumulated rapidly, reaching the highest level after $1 \mathrm{hr}$ of the treatment. Transcripts for FaCOR78 accumulated readily, after $1 \mathrm{~h}$ of CA treatment, and were generally more responsive to CA treatment than to LT. Thus, the orthologs of cold-responsive genes, FaCOR47 and FaCOR 78, were expressed in response to both CA and LT in strawberry. Previous studies have shown the induction of cold-responsive genes in response to cold acclimation and their role in inducing freezing tolerance in wide range of plant species (Guy et al., 1990; Thomashow, 1999). Furthermore, expression of orhthologs of cold-responsive transcription factors has been observed in a number of plant species including strawberries (Jaglo 
et al., 2001; Gao et al., 2002; Owens et al., 2002; Dubouzet et al., 2003), and their role in conferring freezing tolerance in a wide range of plant species appears to be similar to that of well-characterized Arabidopsis cold-responsive genes (Jaglo et al., 2001; Owens et al., 2002).

In addition to their response to cold acclimation, FaCOR47 and FaCOR78 genes were also expressed in response to water stress in strawberry plants (Fig. 3B). A large accumulation of transcripts of FaCOR47 occurred after withholding water from plants for 9 days while moderate transcript accumulation for FaCOR78 was noted after 6 days of water withholding. The expression of these genes corresponded to a significant decrease in water potential of leaves (Fig. 2A) and also to a significant increase in freezing tolerance (Fig. 2B).

As water stress appears to be an integral part of cold acclimation, the molecular responses to cold and water stress show a great deal of similarities. In response to cold, both cold- and drought-responsive genes are induced, and the overlapping pathways resulting in tolerances to these stresses have been reviewed by Shinozaki and Yamaguchi-Shinozaki (2000). The obvious reasons for these similarities is because these genes are regulated a cis-acting C-repeat (CRT) or dehydration-responsive element (DRE) in their promoter regions, both of these contain a common core motif and are, therefore, activated in response both cold and water stress (Yamaguchi-Shinozaki and Shinozaki, 1994). As typical cold acclimation involves both low temperatures and water stress, it is likely that we observe an overlap or similarities in their responses to these environmental cues. The similarities in plants' response to freezing stress and water stress are supported by the studies from Haake et al. (2002) who identified a CBF homolog, CBF4, which responds to only water stress but its overexpression resulted in upregulation of both cold and drought-responsive genes leading to increase in tolerance to both freezing and drought. Also, several previous studies have demonstrated that the overexpression 
of cold-responsive transcription factors, $\mathrm{CBF}$ or $\mathrm{CBF}$ orthlogs, leads to the expression of cold and drought inducible genes, resulting in an increased tolerance to both freezing and drought (Liu et al., 1998; Kasuga et al., 1999; Dubouzet et al., 2003). All these studies point to similarities in plants' responses to cold and drought, which may arise from the fact that cold acclimation process incorporates both low temperature and water stress. Strawberry plants can respond to these cues independently while their response is somewhat similar.

\section{Conclusions}

In summary, we have examined two primary components of cold acclimation in strawberry, namely low temperature and the resulting water stress in the plants. Both of these components contribute to the induction of freezing tolerance during cold acclimation. However, the major component is the water stress during cold acclimation, which can induce significant level of freezing tolerance in strawberry. Indeed, both water stress and low temperature resulted in the expression of COR47, and COR78 orthologs in strawberry, suggesting that both of these factors may have similar, but additive effect on freezing tolerance. However, these two components of cold acclimation can independently induce similar molecular responses in strawberry. 


\section{References}

Campoli, C., Matus-cadiz, M.A., Pozniak, C.J., Cattivelli, L., Fowler, D.B., 2009. Comparative expression of Cbf genes in the Triticeae under different acclimation induction temperatures. Mol. Genet. Genomis 282, 141-152.

Carvallo, M.A., Pino, M., Jeknic, Z., Zou, C., Dohhherty, C.J., Shiu, S., Chen, T.H.H., Thomashow, M.J., 2011. A comparison of the low temperature transcriptomes and CBF regulons of three plant species that differ in freezing tolerance: Solanum commersoni, Solanum tuberosum, and Arabidopsis thaliana. J Exp. Bot. doi:10.1093/jxb/err066.

Chen, H., Li, P. H., 1978. Interactions of low temperature, water stress, and short days in induction of stem frost hardiness in red osier dogwood. Plant Physiology 62, 833-835.

Chen, P., Li, P.H., Weiser C.J., 1975. Induction of frost hardiness in red-osier dogwood stems by water stress. HortScience 10, 372-374.

Cloutier, Y., Andrews, C.J., 1984. Efficiency of cold hardiness induction by desiccation stress in four winter cereals, Plant Physiol. 76, 595-598.

Cloutier, Y., Siminovitch, D., 1982. Correlation between cold-and drought-induced frost Hardiness in winter wheat and rye varieties. Plant Physiol. 69:256-258.

Cox, W. and J. Levitt. 1976. Interrelations between environmental factors and freezing resistance of cabbage leaves. Plant Physiol. 57, 553-558.

Dubouzet, J.G., Sakuma, Y., Ito, Y., Kasuga, M., Dubouzet, E.G., Miura, S., Seki, M., Shinozaki, K., Yamaguchi-Shinozaki, K., 2003. OsDREB genes in rice, Oryza sativa L., encode transcription activators that function in drought- high-salt- and cold-responsive gene expression. Plant J. 33, 751-763. 
Fan, L., Zheng, S., Wang S., 1997. Antisense suppression of phospholipase D $\alpha$ retards abscisic acid and ethylene promoted senescence in postharvest Arabidopsis plants. Plant Cell 9, 2183-96.

Gao, M.J., Allard, G., Byass, L., Flanagan, A.M., Singh., J., 2002. Regulation and characterization of four CBF transcription factors from Brassica napus. Plant Mol. Biol. 49, 459-471.

Guy, C.L., 1990. Cold acclimation and freezing stress tolerance: role of protein metabolism. Annual Review of Plant Physiology and Plant Molecular Biology 41, 187-223.

Guy, C., Haskell, D., Neven, L., Klein, P., Smelser, C., 1992. Hydration-state-responsive proteins link cold and drought in spinach. Planta 188:265-270.

Haake, V., Cook, D., Riechmann, J.L., Pineda, O., Thomashow, M.F., Zhang, J.Z., 2002. Transcription factor CBF4 is a regulator of drought adaptation in Arabidopsis. Plant Physiol. 130, 639-648.

Howell, G.S., Weiser, C. J., 1970. The environmental control of cold acclimation in apple. Plant Physiol. 45, 390-394.

Hsieh, T.H., Lee, J.T., Chang, Y.Y., Chan, M.T., 2002a. Tomato plants ectopically expressing Arabidopsis CBF1 show enhanced resistance to water deficit stress. Plant Physiol. 130, 618-626.

Hsieh, T.H., Lee, J.T., Yang, P.T., Chiu, L.H., Wang, Y.C., Chan, M.T., 2002b. Heterology expression of the Arabidopsis C-repeat/dehydration response element binding factor 1 gene confers elevated tolerances to chilling and oxidative stresses in transgenic tomato. Plant Physiol. 129, 1086-1094.

Jaglo, K.R., Kleff, S., Amundsen, K.L., Zhang, X., Haake, V., Zhang, J.Z., Deits, T., Thomashow, M.F., 2001. Components of the Arabidopsis C-repeat/dehydration 
responsive element binding factor cold-response pathway are conserved in Brassica napus and other plant species. Plant Physiol. 127, 910-917.

Kasuga, M., Liu, Q., Miura, S., Yamaguchi-Shinozaki, K., Shinozaki, K., 1999. Improving plant drought, salt, and freezing tolerance by gene transfer of a single stress inducible transcription factor. Nat. Biotechnol. 17, 287-291.

Kitashiba, H., Ishizaka, T., Isuzugawa. K., Nishimura, K., Suzuki, T., 2004. Expression of a sweet cherry DREB1/CBF ortholog in Arabidopsis confers salt and freezing tolerance. J. Plant Physiol. 161, 1171-1176.

Lang, V., Mantyla, E., Welin, B., Sundberg, B., Palva. E.T., 1994. Alteration in water status, endogenous abscisic acid content, and expression of rab 18 gene during the development of freezing tolerance in Arabidopsis thaliana. Plant Physiol. 104, 1341-1349.

Levitt, J., 1980. Responses of Plant to Environmental Stress: Chilling, Freezing and High Temperature Stresses, $2^{\text {nd }}$ ed. Academic press, New York.

Liu, Q., Kasuga, M., Sakuma, Y., Abe, H., Miura, S., Yamaguchi-Shinizaki, K., Shinozaki. K., 1998. Two transcription factors, DREB1 and DREB2, with an EREBP/AP2 DNA binding domain separate two cellular signal transduction pathways in drought-and lowtemperature-responsive gene expression, respectively, in Arabidopsis. Plant Cell 10, 13911406.

Mantyla, E, Lang, V., Palva, E. T., 1995. Role of abscisic acid in drought-induced freezing tolerance, cold acclimation, and accumulation of LTI78 and RAB18 proteins in Arabidopsis thaliana. Plant Physiol. 107, 141-148.

McKenzie, J.S., Weiser, C.J., Burke, M. J., 1974. Effects of red and far red light on the initiation of cold acclimation in Cornus stolonifera Michx. Plant Physiol. 53, 783-789.

Oh, M.M., Cary, E.E., C. B. Rajashekar., 2009. Environmental stresses induce health-promoting 
phytochemicals in lettuce. Plant Physiol. Biochem. 47, 578-583.

Owens, C.L., Thomashow, M.F., Hancock, J.F., Iezzoni, A.F., 2002. CBF1 orthologs in sour cherry and strawberry and heterologous expression of CBF1 in strawberry. JASHS 127(4), 489-494.

Pearce, R.S., 1999. Molecular analysis of acclimation to cold, Plant Growth Regul. 29, 4776.

Rajashekar, C.B., Li, P.H., Carter, J.V., 1983. Frost injury and heterogeneous ice nucleation in leaves of tuber-bearing Solanum species; Ice nucleation activity of external source of nucleants. Plant Physiol. 71, 749-755.

Shinozaki, K., Yamaguchi-Shinozaki, K., 2000. Molecular responses to dehydration and low temperature: differences and cross-talk between two stress signaling pathways. Curr. Opin. Plant Biol. 3, 217-223.

Shinozaki, K., Yamaguchi-Shinozaki, K., Seki, M., 2003. Regulatory network of gene expression in the drought and cold stress responses. Curr. Opin. Plant Biol. 6, 410-417.

Siminovitch, D., Cloutier, Y., 1982. Twenty-four-hour induction of freezing and drought tolerance in plumules of winter rye seedlings by desiccation stress at room temperature in dark. Plant Physiol. 69, 250-255.

Steponkus, P.L., 1984. Role of the plasma membrane in freezing injury and cold acclimation. Annu. Rev. Plant Physiol. 35, 543-584.

Thomashow, M.F., 1999. Plant cold acclimation, freezing tolerance genes and regulatory mechanisms. Annu. Rev. Plant Physiol. 50, 571-599.

Yamaguchi-Shinozaki, K., Shinozaki, K., 1994. A novel cis-acting element in an Arabidopsis gene is involved in responsiveness to drought, low-temperature, or high-salt stress. Plant 
Cell 6, 251-264. 

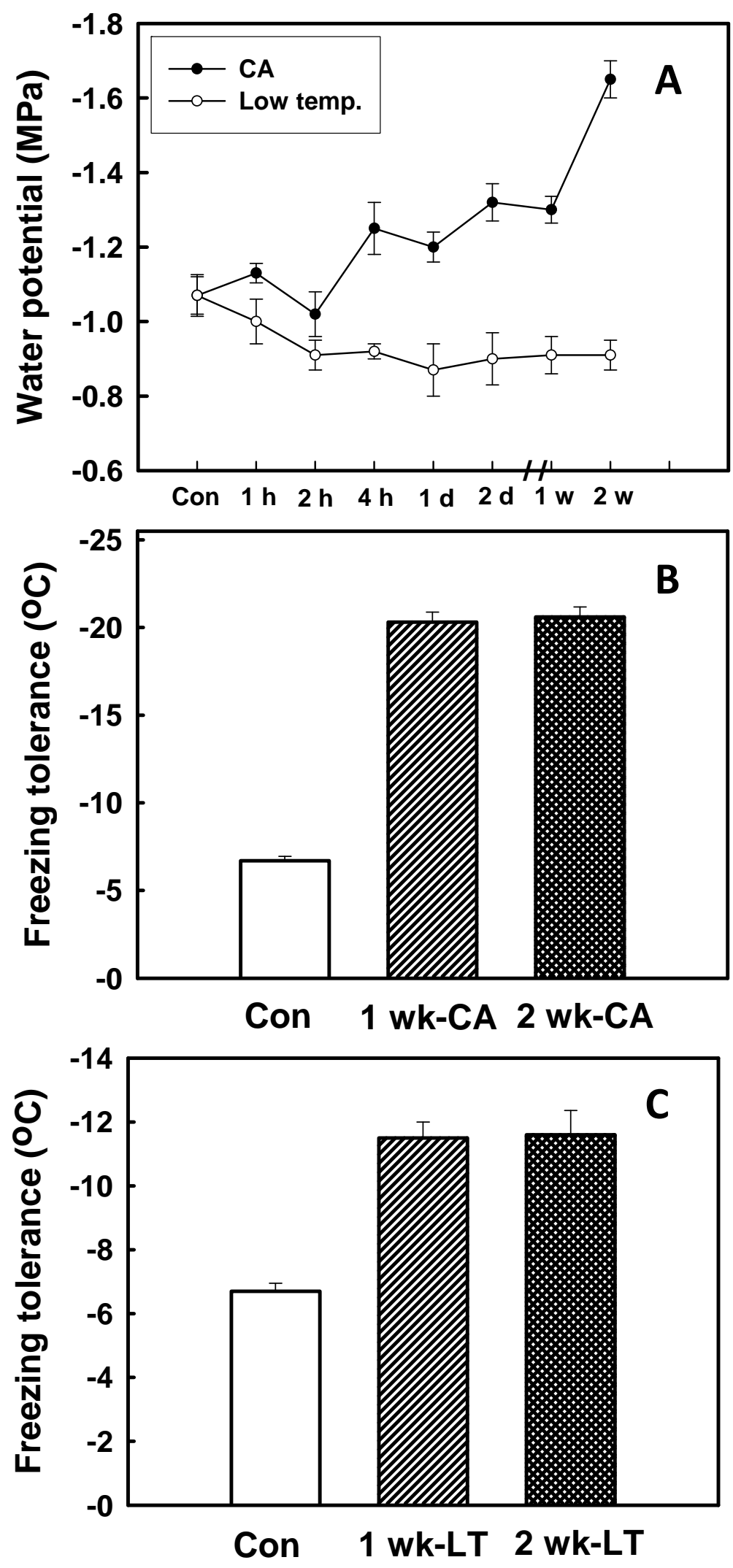

Fig. 1. A- Changes in leaf water potential of strawberry plants in response to typical cold acclimation treatment (solid circles). For cold acclimation treatment, plants were grown at $3 / 1^{\circ} \mathrm{C}$ (day/night temperature) with a 9-h photoperiod for a 2-week period. B- Changes in leaf water potential in response to low temperature without the accompanying water stress (open circle). The growing conditions are identical to those in the cold acclimation treatment outlined above with the exception of the avoidance of the accompanying water stress by growing the plants at $100 \%$ relative humidity and with soil moisture kept at field capacity. $\mathrm{B}$-Changes in freezing tolerance in response to typical cold acclimation treatment. C- Changes in freezing tolerance in response to low temperature without the accompanying water stress. Values represent mean with $\mathrm{SD}(\mathrm{n}=3)$. Freezing tolerance increase after 1 or 2 weeks of CA or LT treatment was significant compared to control ( $\mathrm{t}$ test, $\mathrm{p}=0.01$ ). 

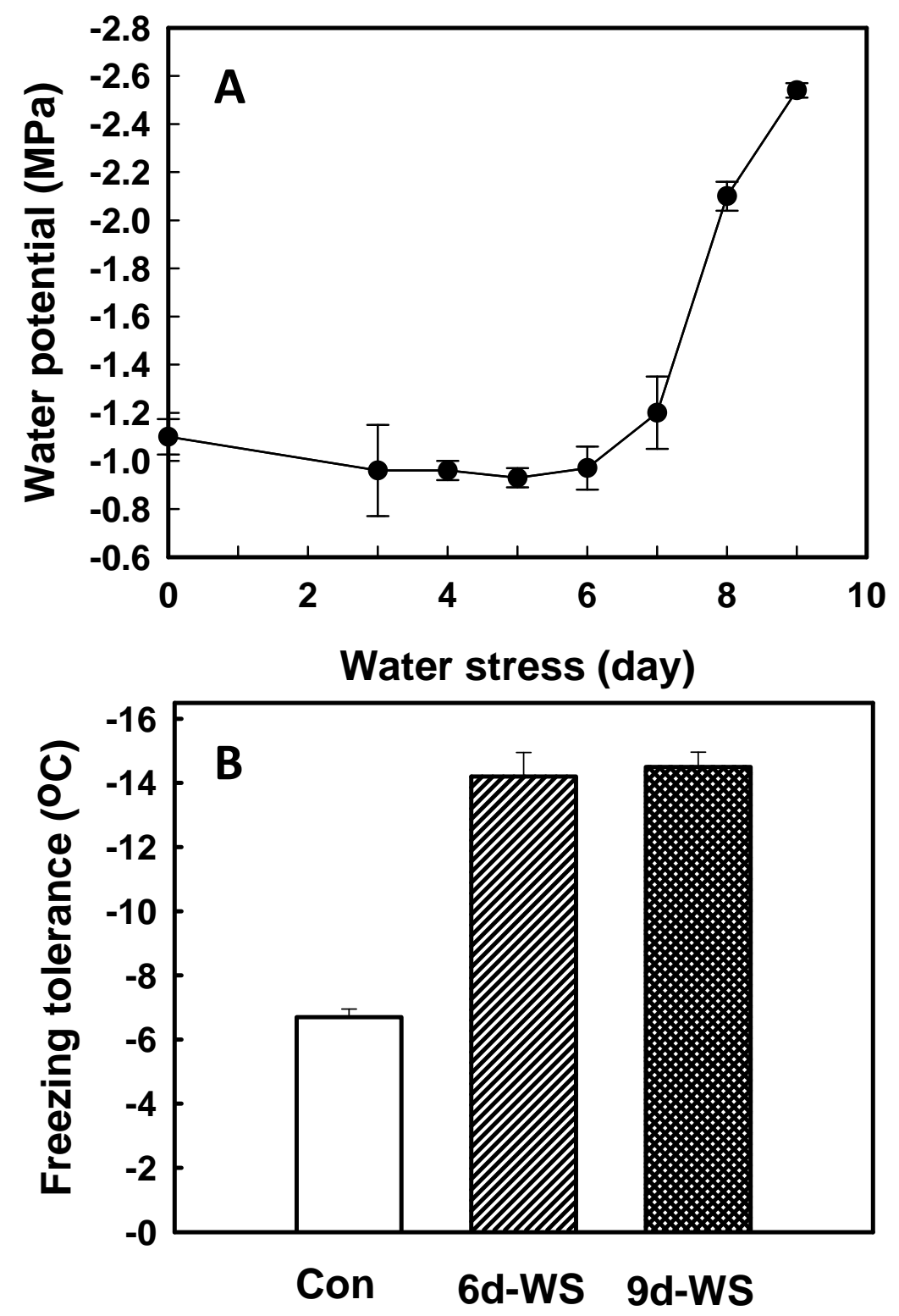

Fig. 2. A- Changes in leaf water potential of strawberry plants during water stress. Water stress was induced in plants by withholding watering for 10 days in a growth chamber. B- Changes in freezing tolerance in response to water stress. Values represent mean with $\mathrm{SD}(\mathrm{n}=3)$. Freezing tolerance increase after $6 \mathrm{~d}$ or $9 \mathrm{~d}$ of water stress was significant compared to control ( $\mathrm{t}$ test, $\mathrm{p}=0.01$ ). 

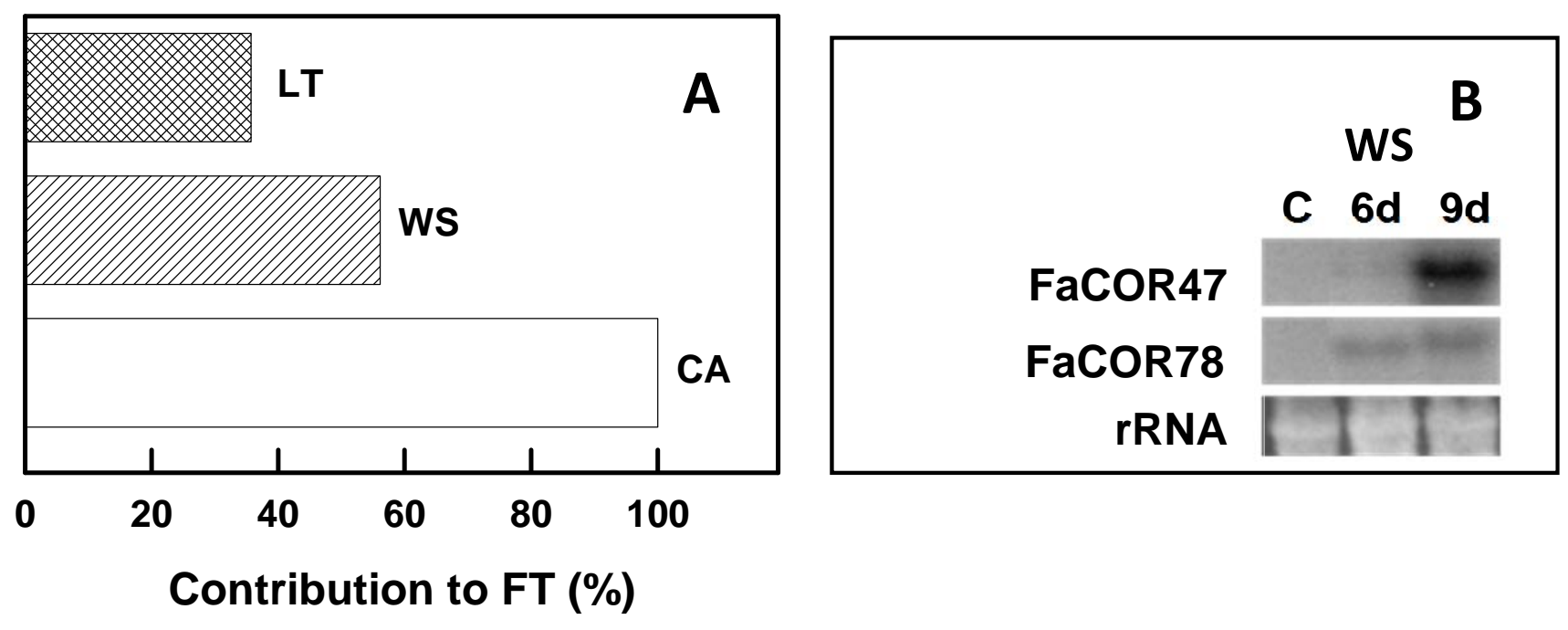

CA

LT

C

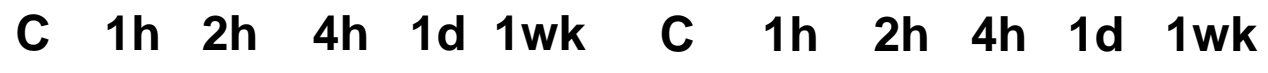

\section{FaCOR47}

FaCOR78

rRNA
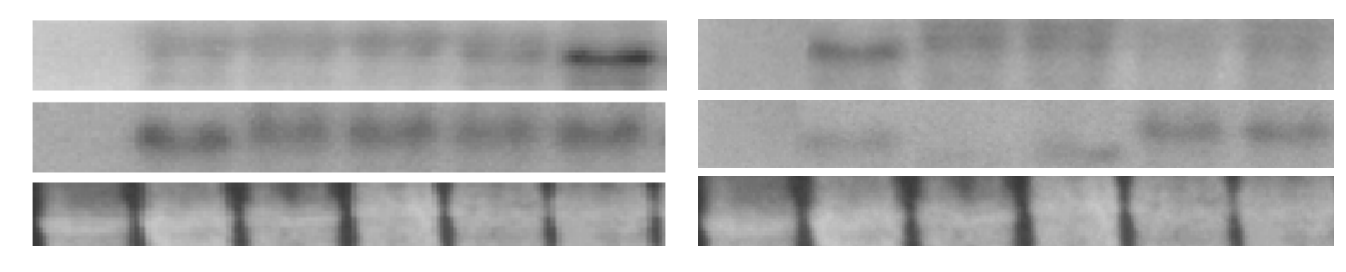

Fig. 3. A- Contribution to freezing tolerance in strawberry plants due to low temperature without water stress (LT), water stress (WS), and cold acclimation (CA). B- Expression of orthologs of coldresponsive genes in response to water stress over a 9-day period. Water stress was imposed as described in fig. 2A. C- Expression of orthologs of cold-responsive genes in response to cold acclimation (CA) and low temperature without the accompanying water stress (LT) over a period of 1 week. The treatment conditions were as described in fig. 1A. r-RNA was used as a loading standard. 